\title{
Benign paroxysmal positional vertigo following whiplash injury: a myth or a reality?
}

\author{
Francesco Dispenza, MD ${ }^{\mathrm{a}, *}$, Alessandro De Stefano, $\mathrm{MD}^{\mathrm{b}}$, Navneet Mathur, $\mathrm{MS}^{\mathrm{c}}$, \\ Adelchi Croce, $\mathrm{MD}^{\mathrm{b}}$, Salvatore Gallina, $\mathrm{MD}, \mathrm{PhD}^{\mathrm{d}}$ \\ ${ }^{a}$ Dipartimento Discipline Chirurgiche ed Oncologiche-UO Otorinolaringoiatria, Università degli Studi di Palermo, Italia \\ ${ }^{\mathrm{b}}$ Dipartimento di Scienze Chirurgiche, Sperimentali e Cliniche-UO Otorinolaringoiatria, Università degli Studi "G. d'Annunzio" Chieti-Pescara, Italia \\ ${ }^{\mathrm{c}} R N T$ Medical College, Udaipur, India \\ ${ }^{\mathrm{d}}$ Dipartimento Neuroscienze Cliniche-UO Otorinolaringoiatria, Università degli Studi di Palermo, Italia \\ Received 19 March 2010
}

\begin{abstract}
Objective: The aim of the study was to evaluate the true incidence, diagnosis, and treatment of benign paroxysmal positional vertigo (BPPV) arising after whiplash injury and to distinguish this type of posttraumatic vertigo from other types of dizziness complained after trauma.

Methods: This was a retrospective study comprising patients referred to our center after whiplash injury. The patients were evaluated with neurotologic examination including bedside and instrumental tests. A Dizziness Handicap Inventory evaluating the symptoms of patients was submitted before and after treatment and was evaluated. The BPPV patients were separately evaluated from those with cervicogenic vertigo, and a comparison between our data about idiopathic BPPV was done.

Results: Eighteen patients of whiplash who had BPPV were evaluated. The mean age was 38.2 years. BPPV was the cause of vertigo in $33.9 \%$ of total whiplash patients. In 16 cases, the posterior semicircular canal was involved; the lateral semicircular canal was involved in 2 cases. The instrumental neurotologic assessment did not show any alteration of either vestibulospinal reflexes or dynamic ocular movements. Duration of symptoms before treatment ranged from 3 to 26 days. A total of $55.5 \%$ of patients had relief from their symptoms after first repositioning maneuver. The Dizziness Handicap Inventory score improved in all patients treated with repositioning maneuvers, but no difference emerged with idiopathic BPPV data.

Conclusion: BPPV after whiplash injury could be unveiled with a simple bedside examination of peripheral vestibular system, and a treatment could be done in the same session. The diagnosis of posttraumatic BPPV is not different from the idiopathic form, but the treatment may require more maneuvers to achieve satisfactory results.

(C) 2011 Elsevier Inc. All rights reserved.
\end{abstract}

\section{Introduction}

The equilibrium is the result of a perfect integration of input from eyesight, proprioceptive receptors, and labyrinths. The whiplash injury is a traumatic lesion due to rapid flexion-extension movement of the cervical column. This

* Corresponding author. Dipartimento Discipline Chirurgiche ed Oncologiche-UO Otorinolaringoiatria, Università degli Studi di Palermo, Via Paolo Emiliani Giudici 37, 90127 Palermo-Italy. Tel.: +393334565471.

E-mail address: francesco.dispenza@gmail.com (F. Dispenza). causes disturbance signals reaching from the cervical proprioceptive system to the central vestibular system and thus has an adverse effect on equilibrium. Balance problems affect $5 \%$ to $50 \%$ of patients of whiplash injury $[1,2]$. The whiplash injury is generally due to car collision and is the first cause of insurance claims. About $15 \%$ to $20 \%$ of cases develop the so-called late whiplash syndrome with persistent complaints including headache, vertigo, instability, nausea, and tinnitus [2].

The cervical trauma may increase the discharge of muscles' proprioceptive receptors of the neck [3] and may 
interfere with normal activity of vestibular system, resulting in an alteration of vestibular-ocular reflexes $[4,5]$. The neck pain, and related balance impairment, is the most common symptom and may be the cause of the symptoms complained by patients that is generally called cervicogenic vertigo.

The quantification of vestibular damage is difficult in forensic cases. For these reasons, it is mandatory to detect maligners and distinguishing them from patients with true disequilibrium disturbance [6].

Labyrinthine vertigo and auditory disturbances are present in $25 \%$ and $17 \%$ of subjects, respectively [7]. The incidence of dizziness with even mild head injury ranges from $15 \%$ to $78 \%$, probably because of an unclear definition of the trauma and of the concept of dizziness [8-10].

Benign paroxysmal positional vertigo (BPPV) is the most frequent cause of peripheral vertigo [11]. It accounts for approximately $24 \%$ of all cases of peripheral vestibular disorders [12]. This type of vertigo is generally seen in individuals 40 years and older, with the highest incidence between 50 and 70 years [13].

The exact etiology of BPPV is still debatable. More than $50 \%$ of all reported cases are idiopathic in nature [14]. Adler [15] was the first to describe manifestations of BPPV in posttraumatic cases. Classic BPPV involves the posterior semicircular canal (PSC) and represents the most common type of BPPV [13,16-18].

Diagnosis of BPPV is based mainly on history of characteristic positional vertigo along with the classic clinical signs. Symptoms are characterized by rotating vertigo with nausea and vomiting, elicited by movements of the head. The nystagmus typically has a latency (of few seconds) and is of limited duration (10-20 seconds), transient, and fatigable [16].

In patients of BPPV, correct diagnostic evaluation and appropriate management, in the great number of cases, solve the problem quickly, without the need for any medical treatment [19].

Our work's aims were to analyze the patients affected by BPPV after whiplash injury and to evaluate differences between idiopathic BPPV and so-called cervicogenic vertigo.

\section{Materials and methods}

A retrospective study of patients of whiplash injury who visited our department between January 2008 and September 2009 was conducted. Patients with a diagnosis of BPPV following the trauma, occurring within 1 week before presentation, were evaluated. The exclusion criteria were history of vertigo before the whiplash injury, history of ear diseases or hearing loss, central nervous system pathology, psychiatric diseases, and history of vascular diseases. The evaluation included clinical history, complete head and neck examination, clinical vestibular tests, pure tone audiometry, and videoculography/videonystagmography with infrared system (ULMER, Synapsis Inc, Marseille, France). The smooth-pursuit function was evaluated by following an oscillating lighted target on a 29 -in screen. The target velocity was regular $(18 \% \mathrm{~s})$; and the oscillating movements were from center to right, back to the center, and center to left. Each trial was of 20 cycles of 57 seconds each. The saccadic test was performed by watching the target on a horizontal plane; the frequency was $0.4 \mathrm{~Hz}$, and the amplitude was $\pm 20^{\circ}$. The parameters analyzed in saccadic movement evaluation were latency, velocity, and accuracy. Our cutoff parameters to consider results as pathologic were as follows: value more than 200 milliseconds for latency, a score less than $77 \%$ for accuracy, and a highest velocity less than $530 \%$ s. The smooth-pursuit movement analysis was evaluated measuring the gain (eye velocity/ target velocity), and the parameter of normality was a value of $0.88 \pm 0.2$.

The same operator performed all instrumental tests.

The Dizziness Handicap Inventory (DHI) was used as reference for clinical improvement and was submitted at first contact and during the follow-up.

The clinical vestibular tests used to investigate the positioning nystagmus were the Dix-Hallpike and McClure-Pagnini tests (nystagmus observed in a supine position while turning the head to the left and right). The vestibulospinal function was evaluated by the Romberg test, index deviation test, and Unterberger test [20]. The dynamic ocular bedside examination included the headshaking test and Halmagyi test. The evaluation of nystagmus and vestibular reflexes was done after a period of at least 5 days from last dosage of vestibular suppressant drugs.

Imaging is generally included in those patients with uncommon clinical presentation or those with lack of response to treatment [21].

After diagnosing BPPV, all patients were promptly treated with canalith repositioning maneuver (CRM) according to the affected semicircular canal. The Semont maneuver or the Epley maneuver was used to treat a PSC BPPV; the Gufoni maneuver was used to manage the lateral semicircular canal (LSC) BPPV [19] The persistence of nystagmus and vertigo spells after CRM was indicative of treatment failure, and repetition of maneuver was done in the same session or in the following 3 days. No medical treatment was prescribed to patients after CRM. The follow-up was done at 1 week, 3 weeks, and 1 month; the patients were examined, and a DHI questionnaire was submitted at the second and sixth months after the treatment.

The patients with cervicogenic vertigo were treated with a combination of physiotherapy, habituation exercises, and analgesics.

Finally, the data where matched with our result in treating idiopathic BPPV $[19,22]$ and with patients complaining a "cervicogenic vertigo" following a whiplash injury to evaluate the differences.

Our Institutional Board reviewed and approved the study. 


\section{Results}

Out of 53 patients of whiplash injury who were referred to our department, 33 were male. The mean age was 40.77 (range, 18-66) years. In all patients, the head trauma occurred within 1 week before presentation.

In 20 patients, the history revealed the presence of rotating vertigo after trauma. An unspecified imbalance or dizziness was the chief complaint in 33 patients, which were labeled as having cervicogenic vertigo. These patients did not show any alteration on neurotologic examination. The hearing was normal in all patients.

In 18 of 20 patients, the vertigo was related to head position and movement on the bed. In the remaining 2 cases, a labyrinthine concussion was diagnosed; and these 2 patients were excluded from present analysis. No patient reported history of vertigo before the head trauma.

The result of the Dix-Hallpike diagnostic maneuver was positive in 16 of 18 patients, whereas the result of the McClure-Pagnini maneuver for the LSC was positive in 2 cases.

Out of 18 whiplash patients with BPPV, 11 were male. The mean age of the group was 38.2 (range, 25-66) years. The BPPV was the cause of vertigo in $33.9 \%$ of whiplash patients. In 16 cases, PSC was involved, the right side in 9 patients and left side in 7 cases. The left LSC was involved in the remaining 2 cases. The neurotologic assessment did not show any alteration of either vestibulospinal reflexes or dynamic ocular movement (Table 1).

Symptoms duration before treatment ranged from 3 to 26 days. A symptoms-free period was present in all cases, with recurrence of vertigo spells after a period ranging from 1 week to 1 month.

The DHI score improved in all patients treated with CRM, as shown in Table 2. Although the improvement was remarkable if compared with cervicogenic vertigo results, no difference emerged with DHI after treatment of idiopathic BPPV.

Table 1

Analysis of eye movement results of the patients

\begin{tabular}{lccc}
\hline & $\begin{array}{l}\text { Idiopathic BPPV } \\
(110 \text { cases })\end{array}$ & $\begin{array}{l}\text { Cervicogenic } \\
\text { vertigo }(33 \text { cases })\end{array}$ & $\begin{array}{l}\text { Posttraumatic } \\
\text { BPPV }(18 \text { cases })\end{array}$ \\
\hline $\begin{array}{c}\text { Smooth-pursuit } \\
\text { gain (SD) }\end{array}$ & $0.87( \pm 0.04)$ & $0.86( \pm 0.03)$ & $0.87( \pm 0.04)$ \\
$\begin{array}{c}\text { Saccadic } \\
\text { velocity, } \\
\text { \%s (SD) }\end{array}$ & $571( \pm 34.1)$ & $572.05( \pm 24.35)$ & $565.9( \pm 27.47)$ \\
$\begin{array}{c}\text { Saccadic } \\
\text { latency, } \\
\text { \% (SD) }\end{array}$ & $155.3( \pm 13)$ & $161.73( \pm 13.07)$ & $155.4( \pm 14.35)$ \\
$\begin{array}{c}\text { Saccadic } \\
\text { accuracy, } \\
\% \text { (SD) }\end{array}$ & $0.83( \pm 0.06)$ & $0.83( \pm 0.06)$ & $0.84( \pm 0.06)$ \\
\hline
\end{tabular}

The patients with cervicogenic vertigo and posttraumatic BPPV due to whiplash injury.
Table 2

Dizziness Handicap Inventory in the patients pre- and posttreatment

\begin{tabular}{lll}
\hline & DHI pretreatment & DHI posttreatment (last) \\
\hline Idiopathic BPPV & Severe: 75 & Severe: 0 \\
& Moderate: 33 & Moderate: 1 \\
& Low: 2 & Low: 109 \\
Posttraumatic BPPV & Severe: 15 & Severe: 0 \\
& Moderate: 3 & Moderate: 0 \\
& Low: 0 & Low: 18 \\
Cervicogenic vertigo & Severe: 9 & Severe: 3 \\
& Moderate: 18 & Moderate: 15 \\
& Low: 6 & Low: 11 \\
\hline
\end{tabular}

The patients with cervicogenic vertigo and posttraumatic BPPV due to whiplash injury. The score of DHI is as follows: severe (100-70 points), moderate (69-40 points), and low (39-0 point).

A total of $55.5 \%$ (10 cases) of patients had relief from their symptoms after first CRM. Two CRMs were necessary in $6(33.3 \%)$ patients, including the 2 patients with LSC BPPV. The remaining $2(11.1 \%)$ patients required 3 sessions of CRM to achieve satisfactory results. Comparing these results with the treatment of idiopathic BPPV, we noted that the posttraumatic variant requires more maneuvers to reach curative repositioning of otoliths (Table 3 ).

\section{Discussion}

The effect of trauma on cervical column was first described by Crowe [23] in 1928 and followed by Gray and Abbott [24] in 1953. Significant injuries can occur following even low-speed collision, but simulated accidents have shown that a 5-mph rear-end car crash can result in a positive acceleration of $8.2 \mathrm{G}$ of the head [25].

The whiplash injury is a biomechanical event that produces a distortion of the cervical column causing lesions of several cervical sites, such as the muscles, ligaments, vertebral joints, vessels, and nerves. The typical acute symptoms after whiplash injury includes neck pain, headache, paraesthesia of upper cervical dermatomes, dizziness or imbalance, and tinnitus [26,27]. The majority of patients recover spontaneously after few months of symptomatic treatment. In some patients, the symptoms may persist.

Pathophysiologically, there is central nervous system weakness following a whiplash injury. With respect to inner ear pathology due to whiplash, the exact nature of the lesion

Table 3

Canalith repositioning maneuver needed to reach the curative repositioning of otoliths

\begin{tabular}{lll}
\hline & Idiopathic BPPV & Posttraumatic BPPV \\
\hline 1 CRM & $81 \%$ & $55.5 \%$ \\
2 CRMs & $17 \%$ & $33.3 \%$ \\
$>2$ CRMs & $2 \%$ & $11.1 \%$ \\
\hline
\end{tabular}


is not known; but some possible explanations are transient ischemia by vertebral artery compression, hemorrhage into labyrinth, direct labyrinthine concussion, and noise of the collision.

A neurotologic evaluation should be performed to find a possible cause of symptoms. The examination includes the assessment of peripheral labyrinth and vestibulo-ocular reflex system by means of clinical vestibular tests, caloric test, and videoculography/videonystagmography.

Previous studies have scarcely demonstrated any relationship between peripheral dysfunction and trauma. Some studies present in the literature have shown positional nystagmus and unilateral hyporeflexia in patients of whiplash injury [9,28-33]. Ettlin et al [34] reported peripheral vestibular deficits in only 2 cases among 18 cases after whiplash injury. However, all these reports have not used the standard value as benchmark or any proper control group. In a previous study, we did not find any correlation between trauma and eye movements in patients with recent trauma.

However, the whiplash injury is considered to be a direct cause of the BPPV [35,36] especially when head trauma is associated. The pathophysiology of the classic BPPV as a disorder of otoliths was suspected first by Barany and later supported by Schuknecht $[37,38]$. Following the trauma, the otoliths are detached from the utricle and displaced within the labyrinth. Generally, patients affected by idiopathic BPPV are older than those due to trauma.

The patients experience severe vertigo when rolling in one particular direction in bed and, less frequently, may also report dizziness with head motion. For dizziness occurring at times other than in bed, cervicogenic vertigo must be considered after a whiplash trauma. Head injury may equally affect both labyrinths; thus, bilateral BPPV is expected to occur more frequently in the posttraumatic cases [35,39], although we have not noted a high incidence of bilateral cases in our series.

There is consensus on the incidence of posttraumatic BPPV that accounts for $15 \%$ to $20 \%$ of all cases $[40,41]$.

The diagnosis is confirmed by positional tests (DixHallpike [38], McClure-Pagnini [42]). Establishing a diagnosis of BPPV is beneficial because it is treated by relatively simple physical maneuvers without the need for additional investigations or drug therapy. About $80 \%$ of patients with posterior canal idiopathic BPPV become free of symptoms and signs following a single maneuver [43-46]. The percentage of successful repositioning after the first CRM decreases in posttraumatic cases. Our hypothesis is that it may be due to the increased number of otoliths displaced as consequence of trauma.

Although the improvement of patients affected by BPPV is remarkable after treatment, if compared with cervicogenic vertigo patients as shown in our results, any difference emerged comparing DHI after treatment of idiopathic BPPV vs posttraumatic cases. This may be explicable considering that the pathophysiology of BPPV, even if posttraumatic, is related to the same mechanism of otolith movements into labyrinth.

It is widely believed that a whiplash injury may induce a disorder of neck proprioceptors caused by forces applied to the neck in the course of the accident. We concur with Fischer et al [47] in distinguishing either spontaneous or positional nystagmus arising in certain static head positions from the previously reported "cervical nystagmus" because static labyrinthine stimulation may exist. Several authors have failed to demonstrate a relationship between nystagmus and neck proprioceptors' stimulation $[30,31,48]$.

\section{Conclusions}

A syndrome in which the dizziness is the main complaint often follows a whiplash trauma. With simple bedside examination of peripheral vestibular system, it is possible to find out the patients with true vertigo; and a treatment could be done in the same session. The diagnosis of posttraumatic BPPV is not different from the idiopathic form, but the treatment may require more CRMs to achieve satisfactory results. In addition, the complete neurotologic examination of vestibular system allows us to recognize maligners who complain of vertigo or dizziness with the aim of insurance claim.

\section{References}

[1] Mallinson AI, Longridge NS. Dizziness from whiplash and head injury: differences between whiplash and head injury. Am J Otol 1998;19:814-8.

[2] Claussen CF, Claussen E. Neurootological contributions to the diagnostic follow-up after whiplash injuries. Acta Otolaryngol Suppl 1995;520:53-6.

[3] Nederhand MJ, Jzerman MJ, Hermens HJ, et al. Cervical muscle dysfunction in the chronic whiplash associated disorder grade II (WAD-II). Spine 2000;15:1938-43.

[4] Brandt T, Bronstein AM. Cervical vertigo. J Neurol Neurosurg Psychiatry 2001;71:8-12.

[5] Treleaven J, Jull G, Sterling M. Dizziness and unsteadiness following whiplash injury: characteristic features and relationship with cervical joint position error. J Rehabil Med 2003;35:36-43.

[6] Wallis B, Bogduk N. Faking a profile: can naive subjects simulate whiplash responses? Pain 1996;66:223-7.

[7] Skovron ML. Epidemiology of whiplash. In: Gunzburg R, Szpalski M, editors. Whiplash injuries: current concepts in prevention, diagnosis and treatment of the cervical whiplash syndrome. Philadelphia: Lippincott-Raven; 1998. p. 61-7.

[8] Berman JM, Frederickson JM. Vertigo after head injury: a five-year follow up. J Otolaryngol 1970;7:237.

[9] Toglia JU, Rosenberg PE, Ronis ML. Posttraumatic dizziness; vestibular, audiologic, and medicolegal aspects. Arch Otolaryngol 1970;92:485-92.

[10] Barber HO. Head injury - audiological and vestibular findings. Ann Otol Rhinol Laryngol 1969;78:23.

[11] Asprella Libonati G, Gufoni M, editors. Vertigine parossistica da CSL: manovre di barbecue ed altre varianti XVI Giornate Italiane di Otoneurologia. Revisione critica di venti anni di vertigine parossistica posizionale benignaSorrento (NA): Formenti; 1999. p. 321-36. 
[12] Asprella Libonati G, Gagliardi G, Cifarelli D, et al. Step by step treatment of lateral semicircular canal canalolithiasis under videonystagmoscopic examination. Acta Otorhinolaryngol Ital 2003;23:10-5.

[13] Baloh RW, Jacobson K, Honrubia V. Horizontal semicircular canal variant of benign positional vertigo. Neurology 1993;43:2542-9.

[14] Baloh RW, Yue Q, Jacobson K, et al. Persistent direction-changing positional nystagmus: another variant of benign positional nystagmus. Neurology 1995;45:1297-301.

[15] Adler A. Ueber den einseitigen Drehschwindel. Dtsch Z Nervenheilk 1897;11:358-75

[16] Casani A, Fattori B, Misale M, et al, editors. Terapia delle VPPB del canale semicircolare posteriore. Tecniche a confronto. VII Giornata di Vestibologia PraticaFormenti: Siena; 1998. p. 35-54.

[17] Mc Clure JA. Horizontal canal BPV. Am J Otolaryngol 1985:14.

[18] Nuti D, Vannucchi P, Pagnini P. Benign paroxysmal vertigo of the horizontal canal: a form of canalolithiasis with variable clinical features. J Vest Res 1996;6:173-84.

[19] Riggio F, Dispenza F, Gallina S, et al. Management of benign paroxysmal positional vertigo of lateral semicircular canal by Gufoni's manoeuvre. Am J Otolaryngol 2009;30:106-11.

[20] Unterberger S. Neue objective registrierbare Vestibularis-Drehreaktion, erhalten durch Treten urf der Stelle. Der "Tretversuch". Arch fuer O N u Kehlkopfheilkunde 1938;145:478.

[21] De Stefano A, Dispenza F, Di Trapani G, et al. Meningioma of the cerebello-pontine angle mimicking benign paroxysmal positional vertigo. J Otolaryngol 2008;37:46-8.

[22] De Stefano A, Kulamarva G, Citraro L, et al. Spontaneous nystagmus in benign paroxysmal positional vertigo. Am J Otolaryngol 2010 [in press].

[23] Crowe HE. Injuries to the cervical spine. Paper presented at the meeting of the Western Orthopaedic Association. San Francisco, USA; 1928.

[24] Gray JR, Abbott KH. Common whiplash injuries to the neck. JAMA 1953;152:1698-704.

[25] Henderson B. Putting the $5 \mathrm{mph}$ injury threshold to the test. Pers Injury Law J 2006:12-4

[26] Evans RW. Some observations in whiplash injuries. Neurol Clin 1992;10:975-97.

[27] Compere WE. Electronystagmographic findings in patients with whiplash injuries. Laryngoscope 1968;78:1226-33.

[28] Oosterveld WJ, Kortschot HW, Kingma GG, et al. Electronystagmographic findings following cervical whiplash injuries. Acta Otolaryngol 1991;111:201-5.

[29] Chester Jr JB. Whiplash, postural control, and the inner ear. Spine 1991;16:716-20 [Phila Pa 1976].

[30] Fischer AJ, Huygen PL, Folgering HT, et al. Hyperactive VOR and hyperventilation after whiplash injury. Acta Otolaryngol Suppl 1995;520(Pt 1):49-52.
[31] Fischer AJ, Huygen PL, Folgering HT, et al. Vestibular hyperreactivity and hyperventilation after whiplash injury. J Neurol Sci 1995;132: 35-43.

[32] Pang LQ. The otological aspects of whiplash injuries. Laryngoscope 1971;81:1381-7.

[33] Rubin W. Whiplash with vestibular involvement. Arch Otolaryngol 1973;97:85-7.

[34] Ettlin TM, Kischka U, Reichmann S, et al. Cerebral symptoms after whiplash injury of the neck: a prospective clinical and neuropsychological study of whiplash injury. J Neurol Neurosurg Psychiatry 1992;55:943-8.

[35] Katsarkas A. Benign paroxysmal positional vertigo (BPPV): idiopathic versus post-traumatic. Acta Otolaryngol 1999;119:745-9.

[36] Fitzgerald DC. Head trauma: hearing loss and dizziness. J Trauma 1996;40:488-96.

[37] Schuknecht HF. Cupulolithiasis. Arch Otolaryngol 1969;90: 765-78.

[38] Dix MR, Hallpike CS. Pathology, symptomatology and diagnosis of certain common disorders of the vestibular system. Ann Otol Rhinol Laryngol 1952;61:987-1016.

[39] Gordon CR, Levite R, Joffe V, et al. Is posttraumatic benign paroxysmal positional vertigo different from the idiopathic form? Arch Neurol 2004;61:1590-3.

[40] Baloh RW, Honrubia V, Jacobson K. Benign positional vertigo: clinical and oculographic features in 240 cases. Neurology 1987;37: 371-8.

[41] Hughes CA, Proctor L. Benign paroxysmal positional vertigo. Laryngoscope 1997;107:607-13.

[42] Vannucchi P, Giannoni B, Pagnini P. Treatment of horizontal semicircular canal benign paroxysmal positional vertigo. J Vest Res 1997;7:1-6

[43] Semont A, Freyes G, Vitte E. Curing the BPPV with a liberatory manoeuvre. Adv Oto Rhinol Laryngol 1988;42:290-3.

[44] Epley JM. The canalith repositioning procedure for treatment of benign paroxysmal positional vertigo. Otolaryngol Head Neck Surg 1982;107:399-404

[45] Herdman SJ, Tusa RJ, Zee DS, et al. Single treatment approaches to benign paroxysmal positional vertigo. Arch Otolaryngol Head Neck Surg 1993;119:450-4.

[46] Parnes LS, Price-Jones RG. Particle repositioning manoeuvre for benign paroxysmal positional vertigo. Ann Otol Rhinol Laryngol 1992;102:325-31.

[47] Fischer AJ, Verhagen WI, Huygen PL. Whiplash injury. A clinical review with emphasis on neuro-otological aspects. Clin Otolaryngol Allied Sci 1997;22:192-201.

[48] Holtmann S, Reiman V, Schops P. Zur klinischen Bedeutung zervikookularer Reaktionen. Laryngol Rhinol Otol 1993;72:306-10. 